\title{
The Acute COPD Exacerbation Prediction Tool (ACCEPT): development and external validation study of a personalised prediction model
}

Amin Adibi, $\mathrm{MSc}^{1}$; Don D Sin, $\mathrm{MD}^{2}$; Abdollah Safari, $\mathrm{PhD}^{1}$; Kate M Johnson, $\mathrm{MSc}^{1}$; Shawn D Aaron, $\mathrm{MD}^{5}$, J Mark FitzGerald, $\mathrm{MD}^{3,4}$; Mohsen Sadatsafavi, $\mathrm{MD}, \mathrm{PhD}^{1,3,4}$

Affiliations:

${ }^{1}$ Respiratory Evaluation Sciences Program, Collaboration for Outcomes Research and Evaluation, Faculty of Pharmaceutical Sciences, University of British Columbia, 2405 Wesbrook Mall, Vancouver, British Columbia, Canada V6T 1 Z3.

${ }^{2}$ Division of Respiratory Medicine, Department of Medicine, The UBC Centre for Heart Lung Innovation, St. Paul's Hospital, University of British Columbia, 1081 Burrard Street, Vancouver, British Columbia, Canada V6Z 1 Y6

${ }^{3}$ Institute for Heart and Lung Health, Division of Respiratory Medicine, Faculty of Medicine, University of British Columbia, 7th Floor, 2775 Laurel Street, Vancouver, British Columbia, Canada V5Z 1M9

${ }^{4}$ Centre for Clinical Epidemiology and Evaluation, University of British Columbia, 828 West 10th Avenue, Vancouver, BC, Canada, V5Z 1M9

${ }^{5}$ Ottawa Hospital Research Institute, University of Ottawa, Ontario, Canada K1H 8L6

Corresponding author:

Don Sin, MD

Division of Respiratory Medicine, Department of Medicine, The UBC Centre for Heart Lung Innovation, St. Paul's Hospital, University of British Columbia, 1081 Burrard Street, Vancouver, British Columbia, Canada V6Z 1 Y6

Phone: (604) 806-8346 x68395

E-mail: Don.Sin@hli.ubc.ca

Link to the Protocol: http://resp.core.ubc.ca/show/accept_protocol

Link to the Web App: http://resp.core.ubc.ca/ipress/accept

Keywords: COPD, exacerbation, clinical prediction model, prognosis, precision medicine 


\section{Research in context}

Evidence before this study: Preventing future exacerbations is a major goal in COPD care.

Because of adverse effects, preventative treatments should be reserved for those at a higher risk of future exacerbations. Predicting exacerbation risk in individual patients can guide these clinical decisions. A 2017 systematic review reported that of the 27 identified COPD exacerbation prediction tools, only two had reported external validation and none was ready for clinical implementation. To find the studies that were published afterwards, we searched PubMed for articles on development and validation of COPD exacerbation prediction since 2015, using the search terms "COPD", "exacerbation", "model”, and "validation". We included studies that reported prediction of either the risk or the rate of exacerbations and excluded studies that did not report external validation. Our literature search revealed two more prediction models neither of which was deemed generalisable due to lack of methodological rigour, or local and limited nature of the data available to investigators.

Added value of this study: We used data from three randomised trials to develop ACCEPT, a clinical prediction tool based on routinely available predictors for COPD exacerbations. We externally validated ACCEPT in a large, multinational prospective cohort. To our knowledge, ACCEPT is the first COPD exacerbation prediction tool that jointly estimates the individualised rate and severity of exacerbations. Successful external validation of ACCEPT showed that its generalisability can be expanded across geography and beyond the setting of therapeutic trials. ACCEPT is designed to be easily applicable in clinical practice and is readily accessible as a web application.

\section{Implications of all the available evidence:}

Current guidelines rely on a history of exacerbations as the sole predictor of future exacerbations. Simple clinical and demographic variables, in aggregate, can be used to predict COPD exacerbations with improved accuracy. ACCEPT enables a more personalised approach to treatment based on routinely collected clinical data by allowing clinicians to objectively differentiate risk profiles of patients with similar exacerbation history. Care providers and patients can use individualised exacerbation risk estimates to decide on preventive therapies based on objectively-established or patient-specific thresholds for treatment benefit and harm. COPD clinical researchers can use this tool to target enriched populations for enrolment in clinical trials. 


\begin{abstract}
Background: Accurate prediction of exacerbation risk enables personalised chronic obstructive pulmonary disease (COPD) care. We developed and validated a generalisable model to predict the individualised rate and severity of COPD exacerbations.
\end{abstract}

Methods: We pooled data from three COPD trials on patients with a history of exacerbations. We developed a mixed-effect model to predict exacerbations over one-year. Severe exacerbations were those requiring inpatient care. Predictors were a history of exacerbations, age, sex, body mass index, smoking status, domiciliary oxygen therapy, lung function, symptom burden, and current medication use. ECLIPSE, a multicentre cohort study, was used for external validation.

Results: The development dataset included 2,380 patients (mean 64.7 years, 1373 [57.7\%] men, mean exacerbation rate $1 \cdot 42 /$ year, $0 \cdot 29 /$ year [20.5\%] severe). When validated against all COPD patients in ECLIPSE ( $\mathrm{n}=1819$, mean 63.3 years, 1186 [65.2\%] men, mean exacerbation rate $1 \cdot 20 /$ year, $0 \cdot 27 /$ year $[22 \cdot 2 \%]$ severe), the area-under-curve was $0 \cdot 81$ (95\%CI 0.79-0.83) for $\geq 2$ exacerbations and $0 \cdot 77(95 \% \mathrm{CI} 0 \cdot 74-0 \cdot 80)$ for $\geq 1$ severe exacerbation. Predicted rates were $0 \cdot 25 /$ year for severe and $1 \cdot 31$ /year for all exacerbations, close to the observed rates $(0 \cdot 27 /$ year and $1 \cdot 20 /$ year, respectively). In ECLIPSE patients with a prior exacerbation history $(n=996$, mean 63.6 years, $611(61 \cdot 3 \%)$ men, mean exacerbation rate 1.82/year, 0.40/year [22.0\%] severe), the area-under-curve was $0 \cdot 73(95 \% \mathrm{CI} 0 \cdot 70-0 \cdot 76)$ for $\geq 2$ exacerbations and $0 \cdot 74(95 \% \mathrm{CI} 0 \cdot 70-0 \cdot 78)$ for $\geq 1$ severe exacerbation. Calibration was accurate for severe exacerbations (predicted $=0 \cdot 37 /$ year, observed $=0 \cdot 40 /$ year) and all exacerbations (predicted $=1 \cdot 80 /$ year, observed $=1 \cdot 82 /$ year). The model is accessible at http://resp.core.ubc.ca/ipress/accept.

Interpretation: This model can be used as a decision tool to personalise COPD treatment and prevent exacerbations.

Funding: Canadian Institutes of Health Research (Grant \#155554). 


\section{Background and Objectives}

Chronic Obstructive Pulmonary Disease (COPD) is characterised by symptoms of breathlessness and cough, which worsen acutely during exacerbations. ${ }^{1}$ COPD is known to be a heterogeneous disorder with large variations in the risk of exacerbation across patients. ${ }^{2}$ In clinical practice, a history of two or more exacerbations and one severe exacerbation per year is used to guide therapeutic choices for exacerbation prevention. ${ }^{3}$ However, this approach is clinically limited owing to significant heterogeneity in risk even within those who frequently exacerbate. ${ }^{4}$

Prognostic clinical prediction tools enable personalised approaches to disease management. Despite potential benefits, no such tool is routinely used in the clinical management of COPD. This is unlike COPD-related mortality for which clinical scoring schemes such as the BODE index are available and frequently used. ${ }^{5}$ A 2017 systematic review by Guerra and colleagues identified 27 prediction tools for COPD exacerbations. ${ }^{6}$ Among these, only two reported on the validation of the model and none were deemed ready for personalised COPD management in the clinic. $^{6}$

Here, we describe a new model, the Acute COPD Exacerbation Prediction Tool (ACCEPT), to predict, at an individual level, the rate and severity of COPD exacerbation and report on its performance in an independent external cohort, and explain, using case studies, its potential clinical application. As a decision tool, ACCEPT provides a personalised risk profile that allows clinicians to tailor treatment regimens to the individual needs of the patients.

\section{Methods}

In reporting our prediction model, we have followed recommendations set forth by the Transparent Reporting of a Multivariable Prediction Model for Individual Prognosis or Diagnosis (TRIPOD) Statement. ${ }^{7}$

\section{Target population and source of data}

We developed the model using data from COPD patients, without a prior or current history of asthma, and who had experienced at least one exacerbation over the previous 12 months. We then externally validated the model: 1) in COPD patients regardless of their exacerbation history, and 2) in a subset of COPD patients with at least one exacerbation over the previous 12 months. 
For discovery, we pooled data across all arms of three randomised controlled trials: Macrolide Azithromycin to Prevent Rapid Worsening of Symptoms in COPD (MACRO) ${ }^{8}$, Simvastatin for the Prevention of Exacerbations in Moderate-to-Severe COPD (STATCOPE) ${ }^{9}$, and the Optimal Therapy of COPD to Prevent Exacerbations and Improve Quality of Life (OPTIMAL) ${ }^{10}$. In a secondary analysis, we only used the placebo arms of the trials. We used Evaluation of COPD Longitudinally to Identify Predictive Surrogate End-Points (ECLIPSE) ${ }^{11}$ - an independent longitudinal COPD cohort study - for external validation. The details of each of these studies have been previously published. Briefly, the MACRO study ${ }^{8}$ evaluated the effect of daily lowdose azithromycin therapy on the rate of exacerbations in COPD patients; the STATCOPE study evaluated the effects of daily simvastatin therapy on the rate of exacerbation ${ }^{9}$, and the OPTIMAL study evaluated the effects of tiotropium-fluticasone-salmeterol on the rate of exacerbation compared with tiotropium-fluticasone and tiotropium alone..$^{10}$ In all three trials, which comprised the development dataset, patients who had a history of at least one exacerbation over the previous 12 months were recruited. ECLIPSE, on the other hand, was a multicentre three-year, non-interventional observational study whose primary aim was to characterise COPD phenotypes and identify novel markers of disease progression. ${ }^{11}$ The ECLIPSE study included patients irrespective of their prior history of an exacerbation. Table 1 provides a detailed summary of these studies.

\section{Outcomes}

The outcomes of interest were the rates of exacerbations and severe exacerbations over one year. Exacerbations were the primary outcome of all three trials and a major outcome measure of the ECLIPSE study. All studies used a similar definition of exacerbations, which was based on the criteria endorsed by the Global Initiative for Chronic Obstructive Lung Disease (GOLD) scientific committee. ${ }^{3}$ Briefly, an exacerbation was defined as an acute episode of intensified symptoms that required additional therapy. ${ }^{3}$ Mild exacerbations were defined as those that were treated with short-acting bronchodilators. Moderate exacerbations were those that required the institution of systemic corticosteroids and/or antibiotics and severe exacerbations were those that required an emergency department visit or a hospitalisation. ${ }^{3,8-10}$ 


\section{Predictors}

To minimize the risk of bias, optimism, and overfitting, no data-driven variable selection was performed. We pre-specified predictors based on clinical relevance and the availability of predictors in all the datasets. Predictors included non-severe as well as severe exacerbations over the previous year, baseline age, sex, smoking status, percent predicted post-bronchodilator forced expiratory volume in one second $\left(\mathrm{FEV}_{1} \%\right.$ predicted $\left.^{12}\right)$, St. George's Respiratory Questionnaire (SGRQ) score, body mass index (BMI), and the use of COPD and non-COPD medications as well as domiciliary oxygen therapy during the previous 12 months. COPD medications were defined as long-acting muscarinic receptor antagonists (LAMAs), long-acting $\beta 2$ agonists (LABAs), and inhaled corticosteroids (ICS). In addition to baseline medications, the model adjusted for treatment assignment in the therapeutic trials (azithromycin in MACRO; statins in STATCOPE; LABA/LAMA and ICS in OPTIMAL). To facilitate clinical implementation, a web application was created (based on conversion factors that have been previously published), which enables the use of a COPD Assessment Test (CAT) score in lieu of SGRQ. ${ }^{13}$

\section{Follow up}

We applied administrative censoring at the one-year follow-up time for patients who had data beyond this threshold. The decision to limit predictions to one year was made a priori based on the assumption that predicting exacerbations over this time frame was relevant for clinical COPD management and that prediction accuracy of the model would decrease substantially beyond one year.

\section{Statistical analysis methods}

We used a joint accelerated failure time and logistic model to characterise the rate and severity of exacerbations. We have previously published the details of this approach elsewhere. ${ }^{14}$ In summary, this framework assigns two random-effect terms to each individual, quantifying each individual's specific rate of exacerbation and the probability that once an exacerbation occurs, it will be severe (appendix p 3). For each patient, this framework fully specifies the hazard of all exacerbations (including their severity) at any given point in time during follow-up, enabling different predictions such as the probability of having a specific number of total and severe exacerbations during the next twelve months. 
Table 1 Available datasets with data on the rate, time, and severity of COPD exacerbations

\begin{tabular}{|c|c|c|c|c|c|c|}
\hline Data Source & Design & Intervention & $\begin{array}{l}\text { Study } \\
\text { Period } \\
\text { (Follow- } \\
\text { up) }\end{array}$ & Centres & Inclusion Criteria & Exclusion Criteria \\
\hline \multicolumn{7}{|l|}{ Development } \\
\hline MACRO & $\begin{array}{l}\text { Randomized } \\
\text { trial }\end{array}$ & Azithromycin & $\begin{array}{l}03-2006 \text { to } \\
07-2010 \\
(1 \text { year })\end{array}$ & $\begin{array}{l}17 \text { sites in } \\
\text { US }\end{array}$ & $\begin{array}{l}>40 \mathrm{yr} \text {. Clinical diagnosis of COPD. }>10 \text { pack- } \\
\text { years of smoking. } \mathrm{O}_{2} \text { or systemic glucocorticoids } \\
\text { therapy in the last yr. Hospitalization or ER visit. }\end{array}$ & $\begin{array}{l}\text { Asthma. Exacerbation in the last month. HR } \\
\text { above } 100 / \mathrm{min}_{\mathrm{B}} \mathrm{QT}_{\mathrm{C}}>450 \mathrm{~ms} \text {. } \mathrm{QT}_{\mathrm{C}} \text { prolonging } \\
\text { or TdP-related medication except for } \\
\text { amlodipine. Hearing impairment. }\end{array}$ \\
\hline STATCOPE & $\begin{array}{l}\text { Randomized } \\
\text { trial }\end{array}$ & Simvastatin & $\begin{array}{l}03-2010 \text { to } \\
01-2014 \\
\text { ( 2 years) }\end{array}$ & $\begin{array}{l}45 \text { sites } \\
\text { (29 in US } \\
\text { and } 16 \text { in } \\
\text { Canada) }\end{array}$ & $\begin{array}{l}40-80 \text { yrs. Clinical diagnosis of COPD. }>10 \\
\text { pack-years of smoking. } \mathrm{O}_{2} \text { OR systemic } \\
\text { glucocorticoids OR antibiotics therapy OR } \\
\text { hospitalization OR ER visit in the last yr. }\end{array}$ & $\begin{array}{l}\text { Asthma. Receiving statins, or should have } \\
\text { received statins. On drugs that contradicted } \\
\text { with statins. Unable to take statins. Active liver } \\
\text { disease, alcoholism, or allergy. }\end{array}$ \\
\hline OPTIMAL & $\begin{array}{l}\text { Randomized } \\
\text { trial }\end{array}$ & $\begin{array}{l}\text { Tiotropium in } \\
\text { combination } \\
\text { with } \\
\text { Salmeterol or } \\
\text { Fluticasone- } \\
\text { Salmeterol }\end{array}$ & $\begin{array}{l}10-2003 \text { to } \\
01-2006 \\
(1 \text { year })\end{array}$ & $\begin{array}{l}27 \text { sites in } \\
\text { Canada }\end{array}$ & $\begin{array}{l}>35 \mathrm{yr} \text {. Clinical diagnosis of COPD. }>10 \text { pack- } \\
\text { years of smoking. Exacerbation requiring } \\
\text { systemic glucocorticoids OR antibiotics therapy } \\
\text { in the last yr. }\end{array}$ & $\begin{array}{l}\text { Asthma }<40 \text { yrs. CHF with persistent severe } \\
\text { LVD. Oral prednisone. Intolerance to } \\
\text { tiotropium, salmeterol, or fluticasone-salmeterol. } \\
\text { Glaucoma. Urinary tract obstruction. Lung } \\
\text { transplant or volume reduction. Diffuse bilateral } \\
\text { bronchiectasis. Pregnancy or breastfeeding. }\end{array}$ \\
\hline \multicolumn{7}{|l|}{ Validation } \\
\hline ECLIPSE & Cohort & & $\begin{array}{l}12-2005 \text { to } \\
02-2010 \\
\text { (3 years) }\end{array}$ & $\begin{array}{l}46 \text { sites in } \\
12 \text { countries }\end{array}$ & $\begin{array}{l}40-75 \text { yrs. Clinical diagnosis of COPD. }>10 \\
\text { pack-years of smoking. }\end{array}$ & $\begin{array}{l}\text { Respiratory disorders other than COPD. } \\
\text { Reported exacerbation in the past month. } \\
\text { Significant inflammatory disease. }\end{array}$ \\
\hline
\end{tabular}


Two forms of uncertainty in predictions were quantified: the uncertainty due to the finite sample of the validation set (represented by the $95 \%$ confidence interval $[95 \% \mathrm{CI}]$ around the mean of projected values), and uncertainty due to the differences in patients' specific exacerbation frequency and severity (represented by the 95\% prediction interval around the mean, the interval which has a $95 \%$ probability to contain a future observation of a patient with the same predictors). Shrinkage methods were not applied given the low risk of bias due to complete prespecification of the model and the relatively high events per predictor in the development dataset. ${ }^{15}$ Because in this framework, the correlation between the previous and future exacerbations rates is modelled through random-effect terms, a history of exacerbation did not enter the model as a predictor. Instead, a Bayesian approach was employed to model the distribution of future exacerbation rate and severity, given the exacerbation history of an individual subject (appendix p 4). The availability of full exacerbation history in the external validation cohort enabled validation of this approach.

We performed statistical analyses using SAS (version 9.4) and R (version 3.6.1).

\section{External validation}

We used the first year of follow-up data in ECLIPSE to establish an accurate 1-year history of exacerbation for each patient. Next, we used the second year of follow-up to validate the model. The model was validated first in the entire COPD cohort of ECLIPSE $(n=1,819)$, and then in a subset of COPD patients who had at least one exacerbation in the first year of follow-up (n=996). This subset was similar to the population characteristics of the development dataset, while the full ECLIPSE cohort enabled assessment of the generalisability of the model beyond patients with an exacerbation history.

We examined model calibration (the degree to which the predicted and actual risks or rates of exacerbations aligned) and discrimination (the extent to which the model separated individuals with different risks).${ }^{16}$ Calibration was assessed by comparing the predicted and observed exacerbation rates across subgroups with differential risks, evaluating the calibration plots, and calculating Brier scores (i.e. the mean squared error of forecast). Discrimination was assessed by calculating receiver operating characteristic (ROC) curves, and the area-under-the-curve (AUC), and then comparing them using a DeLong's test. ${ }^{17}$ ROC and AUC calculations were based on the occurrence of two or more exacerbations of any type, or one or more severe exacerbations. ${ }^{3}$ 


\section{Ethics approval}

The study was approved by the University of British Columbia/Providence Health Research Ethics Board (H11-00786).

\section{Role of the funding source}

The funders of the study had no role in study design, data collection, data analysis, data interpretation, or writing of the report. AA, AS, DS (corresponding author), and MS had full access to all of the data and the final responsibility for the publication.

\section{Results}

\section{Participants}

Figure 1 presents the flowchart of the sample selection. We excluded 96 patients who were either lost to follow-up ( $n=33$ ) or had missing values $(n=63)$. The final development dataset included 2,380 patients (1,107 from MACRO, 847 from STATCOPE, and 426 from OPTIMAL; overall mean age 64.7, 1373 [57.7\%] males). Patients experienced a total of 3,056 exacerbations, 628 of which were severe. In the external validation dataset, ECLIPSE, 109 patients had missing values. Thus, the final sample included 1,819 COPD patients (mean age 63·3, 1186 [65.2\%] male). Among these 996 COPD patients had at least one exacerbation in the first year (mean age 63.6, $611[61 \cdot 3 \%]$ male). Figure 2 provides a detailed comparison of the development and validation datasets in terms of demographics, predictors, and outcome variables. The average exacerbation rates in the development dataset, the validation set with all patients, and the validation subset containing only those with a prior history of an exacerbation were $1 \cdot 42,1 \cdot 20$, and $1 \cdot 80$ events/year, respectively. For severe exacerbations, the average rate was $0 \cdot 29,0 \cdot 27$, and $0 \cdot 40$ events/year, respectively. 


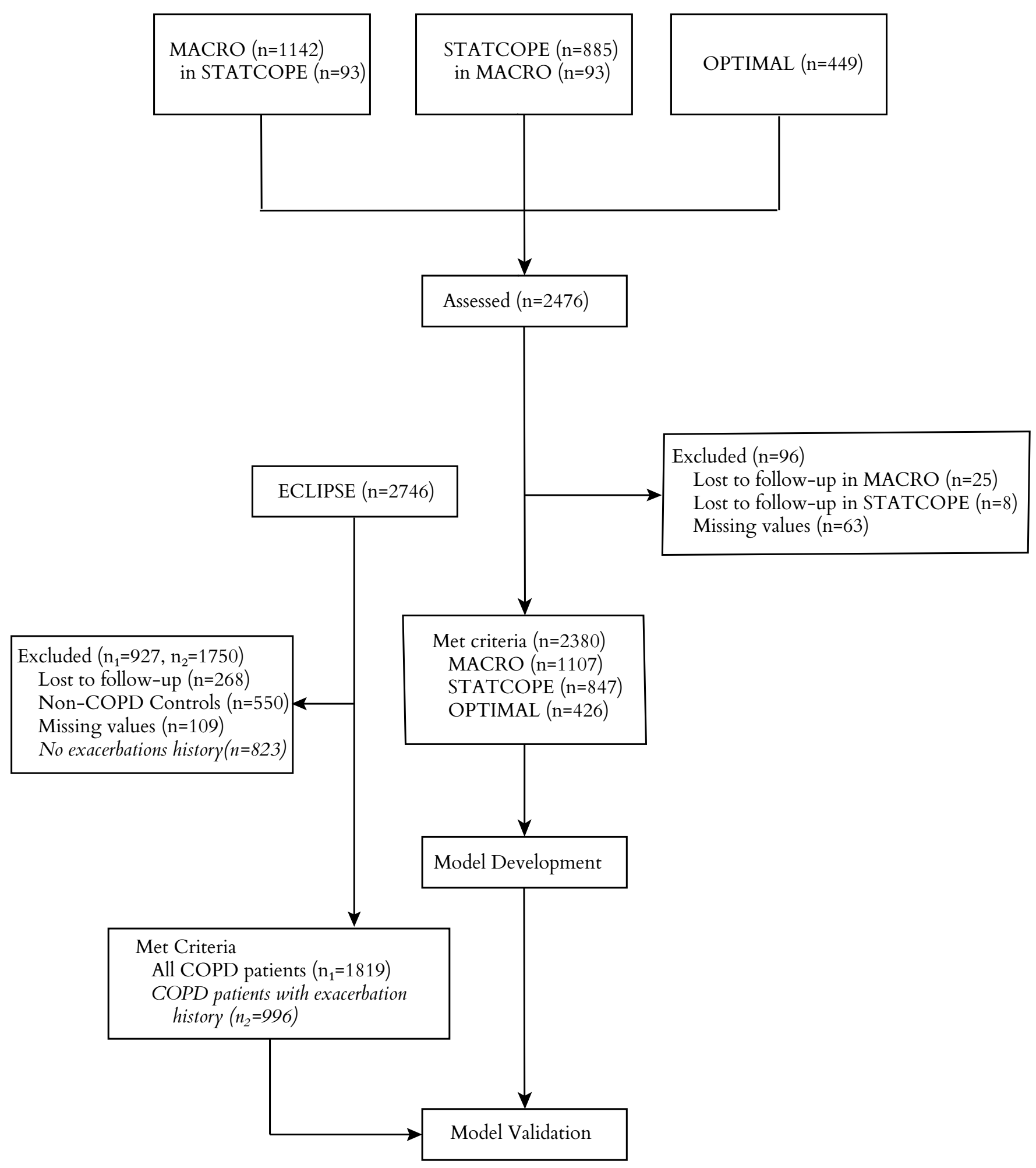

Figure 1 Flow diagram 
Figure 2 Baseline characteristics

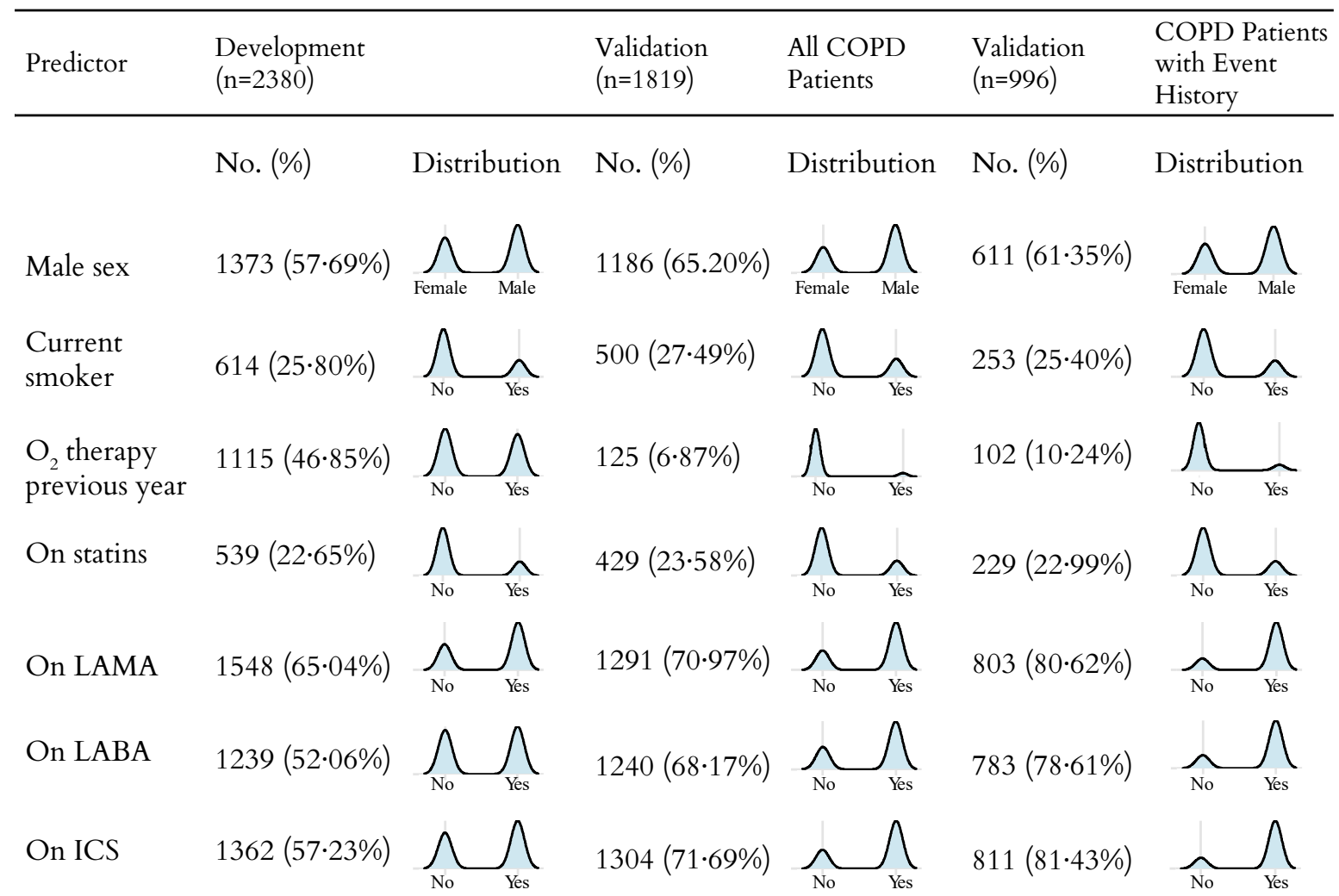

Mean (SD) Distribution Mean (SD) Distribution Mean (SD) Distribution

\begin{tabular}{|c|c|c|c|c|c|c|}
\hline Age, years & $64 \cdot 68(8 \cdot 75)$ & ${ }_{50}{ }_{70} \quad{ }_{90}$ & $63 \cdot 30(6 \cdot 99)$ & $\int_{50}{ }_{70}$ & $63 \cdot 54(6 \cdot 90)$ & $\underbrace{}_{50} \backslash$ \\
\hline Follow-up & $0 \cdot 90(0 \cdot 23)$ & & $0 \cdot 97(0 \cdot 12)$ & Л & $0.97(0 \cdot 13)$ & \\
\hline & & $\begin{array}{lll}0.0 & 0.5 & 1 \cdot 0\end{array}$ & & $\begin{array}{lll}0.0 & 0.5 & 1.0\end{array}$ & & $0 \cdot 0 \quad 0.5$ \\
\hline $\begin{array}{l}\mathrm{FEV}_{1} \\
\% \text { Predicted }\end{array}$ & $40 \cdot 60(15 \cdot 93)$ & 255075 & $48 \cdot 40(16 \cdot 39)$ & 255075 & $44 \cdot 54(15 \cdot 79)$ & \\
\hline SGRQ Score ${ }^{b}$ & $49 \cdot 95(16 \cdot 72)$ & 205080 & $47 \cdot 14(18 \cdot 22)$ & 205080 & $51 \cdot 44(17 \cdot 04)$ & 205080 \\
\hline BMI & $27 \cdot 53(6 \cdot 43)$ & $\begin{array}{ll}18 & 35\end{array}$ & $26 \cdot 55(5 \cdot 80)$ & & $26 \cdot 21(5 \cdot 77)$ & \\
\hline
\end{tabular}
Rate of
Exacerbations $^{c}$ Events/year Distribution Events/year Distribution Events/year Distribution

\begin{tabular}{|c|c|c|c|c|c|c|}
\hline Total & $1 \cdot 42$ & Mhun & 1.20 & Mhill & $1 \cdot 82$ & $\int_{0123456}^{M}$ \\
\hline $\begin{array}{l}\text { Severe or } \\
\text { very severe }\end{array}$ & $0 \cdot 29$ & $\ln$ & 0.27 & $\ln$ & $0 \cdot 40$ & hon \\
\hline
\end{tabular}

Abbreviations: SD, standard deviation; COPD, chronic obstructive pulmonary disease; LAMA, long-acting muscarinic antagonist; LABA, long-acting beta antagonist; ICS, inhaled corticosteroids; FEV1, \% predicted forced expiratory volume in 1 second; SGRQ, St. George's Respiratory Questionnaire; BMI, body mass index. a Data are presented as mean (SD) for continuous predictors and number of subjects (\% of total) for dichotomous predictors, except
where noted.

b Between 0 and 100 , with a higher score indicating worse status.

c Numbers in the \% column show the annual rate of exacerbations (episodes/patient). 
The distribution of baseline predictors among different studies that were included in the development dataset is available in the appendix (pp 5-6). Notably, none of the STATCOPE participants had a history of statin use because patients with cardiovascular comorbidities were excluded from this trial.

We assumed that missing values were missing at random and opted for a complete case analysis given that only 63 out of 2443 patients $(2 \cdot 58 \%)$ in the combined development dataset and 109 out of 1928 patients $(5 \cdot 65 \%)$ in the validation dataset had missing data (appendix p 6).

\section{Model specification and performance}

Table 2 provides coefficient estimates for predictors. Regression coefficients are shown as loghazard ratios (ln-HR) for the rate component and log-odds ratios (ln-OR) for the severity component. The full regression results including coefficients representing adjustments for treatments arms are available in the appendix (p 8). Results remained largely unchanged in the secondary analysis based on placebo arms (appendix p 9).

When validated against all patients in ECLIPSE (including those without an exacerbation history), ACCEPT slightly overestimated their actual overall exacerbation rates (observed 1.20 events/year, predicted 1.31 events/year) but was accurate for severe exacerbation rates (observed $0 \cdot 27$ events/year, predicted $0 \cdot 25$ events/year, Figure $3 A$ ). The same trend was observed in all major risk-factor subgroups (Figure 3A) and in both men and women (Figure 4A). The Brier score was $0 \cdot 20$ for all exacerbations and $0 \cdot 12$ for severe exacerbations. In patients with an exacerbation history, ACCEPT showed robust overall calibration: predicted annual exacerbation rate closely matched the observed rate for all exacerbations (observed 1.82 events/year, predicted 1.80 events/year), severe exacerbations (observed 0.40 events/year, predicted 0.37 events/year), and risk-factor subgroups (Figure 3B). Calibration plots comparing per decile average rate of exacerbations showed good agreement between observed and predicted rates for both female and male patients (Figure 4B). The Brier score was $0 \cdot 17$ for all exacerbations and $0 \cdot 16$ for severe exacerbations. Similar results for the development dataset are provided in the appendix $(p 7)$.

In all COPD patients, the model had an AUC of 0.81 (95\%CI 0.79-0.83) for $\geq 2$ exacerbations and $0.77(95 \% \mathrm{CI} 0 \cdot 74-0 \cdot 80)$ for $\geq 1$ severe exacerbation (Figure $54 A$ ). The corresponding AUCs 
for COPD patients with an exacerbation history were $0 \cdot 73(95 \% \mathrm{CI} 0 \cdot 70-0 \cdot 76)$ for two or more exacerbations and $0 \cdot 74(95 \% \mathrm{CI} 0 \cdot 70-0 \cdot 78)$ for at least one severe exacerbation (Figure 5B).

Compared to the current practice, which relies exclusively on a prior history of exacerbation to predict future risk of a exacerbation, ACCEPT demonstrated higher performance in predicting severe exacerbations in all COPD patients $\left(\mathrm{AUC}_{\mathrm{ACCEPT}}=0 \cdot 77\right.$ vs. $\left.\mathrm{AUC}_{\text {Event History }}=0 \cdot 66, \mathrm{p}<0 \cdot 0001\right)$ and in the subset who had a prior history of an exacerbation $\left(\mathrm{AUC}_{\mathrm{ACCEPT}}=0 \cdot 74 \mathrm{vs}\right.$. $\mathrm{AUC}_{\mathrm{Event}}$ History $=0 \cdot 67, \mathrm{p}<0 \cdot 0001)$. Similarly, ACCEPT showed better performance for all exacerbations regardless of severity (Figure 5). 
Table 2 Model coefficients for the joint rate-severity prediction model of COPD exacerbations

\begin{tabular}{|c|c|c|c|c|c|c|}
\hline \multirow[b]{2}{*}{ Predictor } & \multicolumn{3}{|c|}{ Rate Component } & \multicolumn{3}{|c|}{ Severity Component } \\
\hline & $\begin{array}{l}\text { Estimate } \\
\ln (\mathrm{HR})\end{array}$ & $95 \% \mathrm{CI}$ & $\mathrm{p}$ & $\begin{array}{l}\text { Estimate } \\
\ln (\mathrm{OR})\end{array}$ & $95 \% \mathrm{CI}$ & $\mathrm{p}$ \\
\hline Intercept & $-0 \cdot 009$ & $\begin{array}{l}-0 \cdot 58 \\
0 \cdot 56\end{array}$ & $0 \cdot 974$ & $-3 \cdot 849$ & $\begin{array}{l}-5 \cdot 54,- \\
2 \cdot 16\end{array}$ & $<\cdot 0001$ \\
\hline Male & $-0 \cdot 152$ & $\begin{array}{l}-0 \cdot 25,- \\
0 \cdot 05\end{array}$ & $0 \cdot 003$ & $0 \cdot 377$ & $\begin{array}{l}0 \cdot 08 \\
0 \cdot 67\end{array}$ & $0 \cdot 012$ \\
\hline $\begin{array}{l}\text { Age at baseline (per 10- } \\
\text { year) }\end{array}$ & $-0 \cdot 018$ & $\begin{array}{l}-0 \cdot 08 \\
0 \cdot 05\end{array}$ & $0 \cdot 576$ & $0 \cdot 109$ & $\begin{array}{l}-0 \cdot 07 \\
0 \cdot 29\end{array}$ & $0 \cdot 240$ \\
\hline $\begin{array}{l}\text { Current smoker }{ }^{\mathrm{b}} \text { at } \\
\text { Baseline }\end{array}$ & $-0 \cdot 195$ & $\begin{array}{l}-0 \cdot 32,- \\
0 \cdot 07\end{array}$ & $0 \cdot 003$ & $0 \cdot 390$ & $\begin{array}{l}0 \cdot 03 \\
0 \cdot 75\end{array}$ & $0 \cdot 034$ \\
\hline $\begin{array}{l}\text { Oxygen therapy }{ }^{b} \text { last } \\
\text { year }\end{array}$ & $0 \cdot 085$ & $\begin{array}{l}-0 \cdot 03 \\
0 \cdot 2\end{array}$ & $0 \cdot 162$ & $0 \cdot 538$ & $\begin{array}{l}0 \cdot 2 \\
0 \cdot 88\end{array}$ & $0 \cdot 002$ \\
\hline $\begin{array}{l}\text { Baseline } \mathrm{FEV}_{1}(\% \\
\text { predicted })\end{array}$ & $-0 \cdot 428$ & $\begin{array}{l}-0 \cdot 79,- \\
0 \cdot 07\end{array}$ & $0 \cdot 020$ & $-1 \cdot 119$ & $\begin{array}{l}-2 \cdot 24 \\
0 \cdot 01\end{array}$ & $0 \cdot 051$ \\
\hline $\begin{array}{l}\text { SGRQ Score }{ }^{c} \text { (per 10- } \\
\text { unit) }\end{array}$ & $0 \cdot 100$ & $\begin{array}{l}0 \cdot 07 \\
0 \cdot 13\end{array}$ & $<\cdot 0001$ & $0 \cdot 199$ & $\begin{array}{l}0 \cdot 11 \\
0 \cdot 29\end{array}$ & $<\cdot 0001$ \\
\hline BMI (per 10-unit) & $-0 \cdot 123$ & $\begin{array}{l}-0 \cdot 21,- \\
0 \cdot 04\end{array}$ & $0 \cdot 004$ & $-0 \cdot 103$ & $\begin{array}{l}-0 \cdot 36 \\
0 \cdot 15\end{array}$ & $0 \cdot 434$ \\
\hline $\mathrm{CV}$-indicated statins ${ }^{\mathrm{b}}$ & $0 \cdot 095$ & $\begin{array}{l}-0 \cdot 03 \\
0 \cdot 22\end{array}$ & $0 \cdot 127$ & $0 \cdot 315$ & $\begin{array}{l}-0 \cdot 03 \\
0 \cdot 67\end{array}$ & $0 \cdot 078$ \\
\hline LAMA $^{b}$ & $0 \cdot 144$ & $\begin{array}{l}0 \cdot 03 \\
0 \cdot 25\end{array}$ & $0 \cdot 011$ & $-0 \cdot 134$ & $\begin{array}{l}-0 \cdot 45 \\
0 \cdot 18\end{array}$ & $0 \cdot 402$ \\
\hline $\mathrm{LABA}^{\mathrm{b}}$ & $0 \cdot 118$ & $\begin{array}{l}-0 \cdot 01 \\
0 \cdot 24\end{array}$ & $0 \cdot 066$ & $0 \cdot 012$ & $\begin{array}{l}-0 \cdot 34 \\
0 \cdot 36\end{array}$ & $0 \cdot 946$ \\
\hline $\mathrm{ICS}^{\mathrm{b}}$ & $0 \cdot 216$ & $\begin{array}{l}0 \cdot 09 \\
0 \cdot 34\end{array}$ & $0 \cdot 001$ & $0 \cdot 376$ & $\begin{array}{l}0 \cdot 03 \\
0 \cdot 72\end{array}$ & $0 \cdot 034$ \\
\hline $\begin{array}{l}\text { Random Effect } \\
\text { Variance }\end{array}$ & $0 \cdot 60$ & $\begin{array}{l}0 \cdot 51 \\
0 \cdot 69\end{array}$ & $<\cdot 0001$ & $2 \cdot 385$ & $\begin{array}{l}1 \cdot 63 \\
3 \cdot 14\end{array}$ & $<\cdot 0001$ \\
\hline Random Effect & $0 \cdot 147$ & & $0 \cdot 172$ & & & \\
\hline
\end{tabular}

Abbreviations: CI, confidence interval; FEV1, \% predicted forced expiratory volume in 1 second using Hankinson's method $^{12}$;; SGRQ, St. George's Respiratory Questionnaire; LAMA, long-acting muscarinic antagonist; LABA, long-acting beta antagonist; ICS, inhaled corticosteroids; BMI, body mass index.

${ }^{a}$ All p-values and confidence limits were computed from the final Hessian matrix

based on a $t$ distribution with default degrees of freedom (number of subjects minus number of random effects) in SAS NLMIXED.

${ }^{\mathrm{b}}$ Binary predictor for medication use in the previous 12 months.

${ }^{\mathrm{c}}$ Between 0 and 100, with a higher score indicating worse status. 


\section{Subgroup Calibration Performance of ACCEPT}

\section{A) In all COPD patients in ECLIPSE Study}
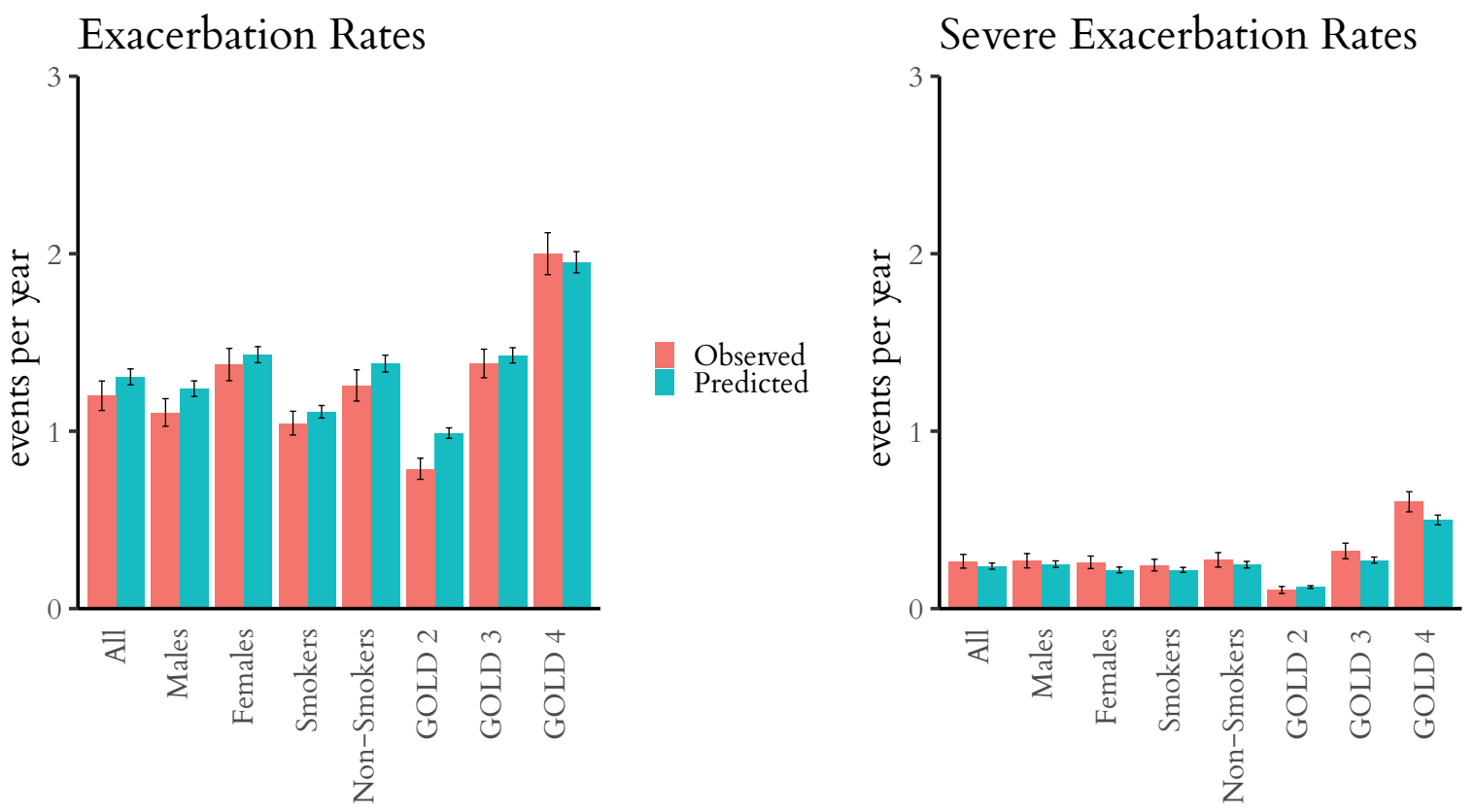

B) In COPD patients with a history of exacerbation in ECLIPSE Study
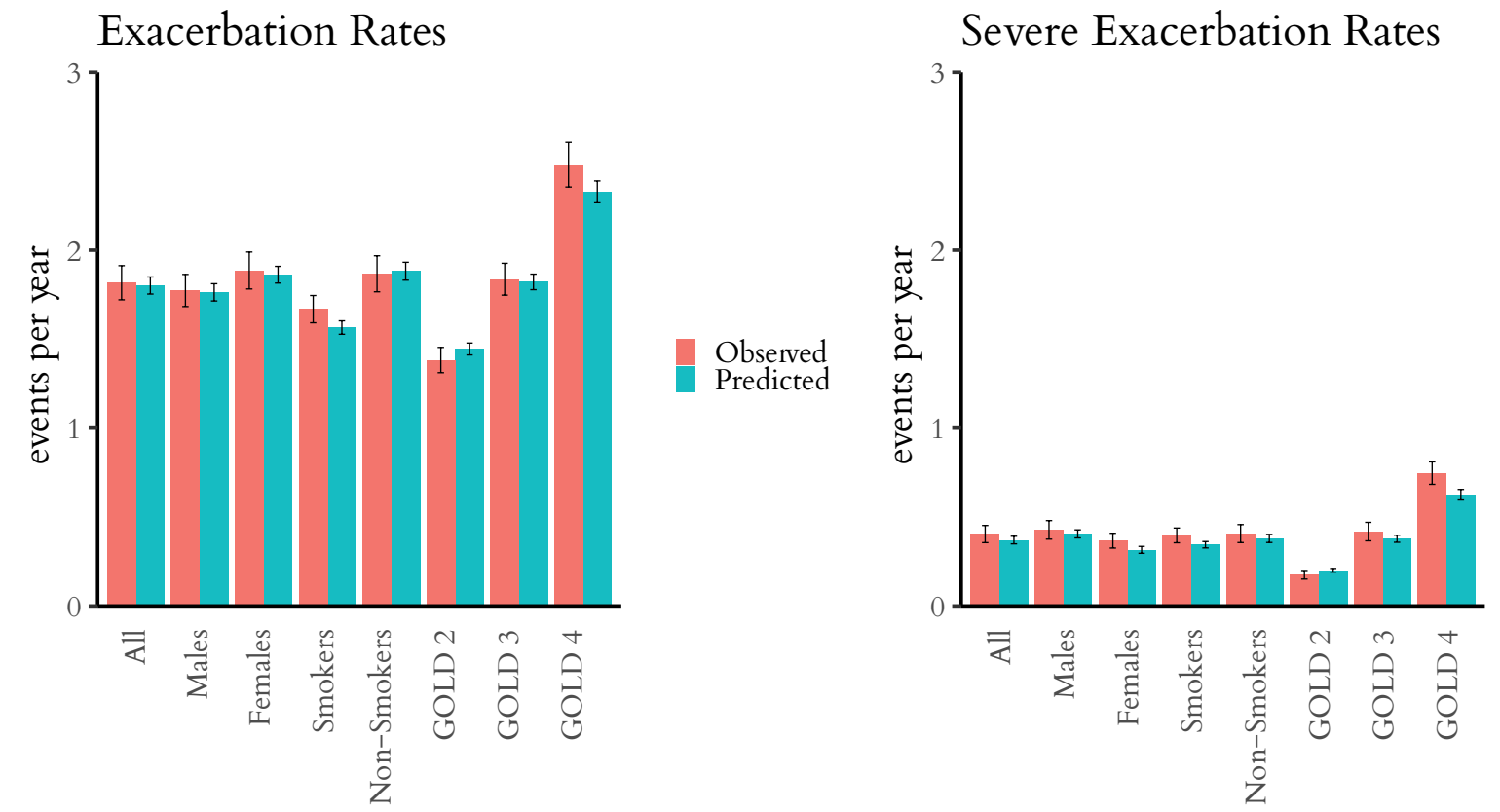

Figure 3 Calibration in risk-factor subgroups 


\section{Calibration Performance of ACCEPT}

\section{A) In all COPD patients in ECLIPSE Study}

Males ( $\mathrm{n}=1186)$

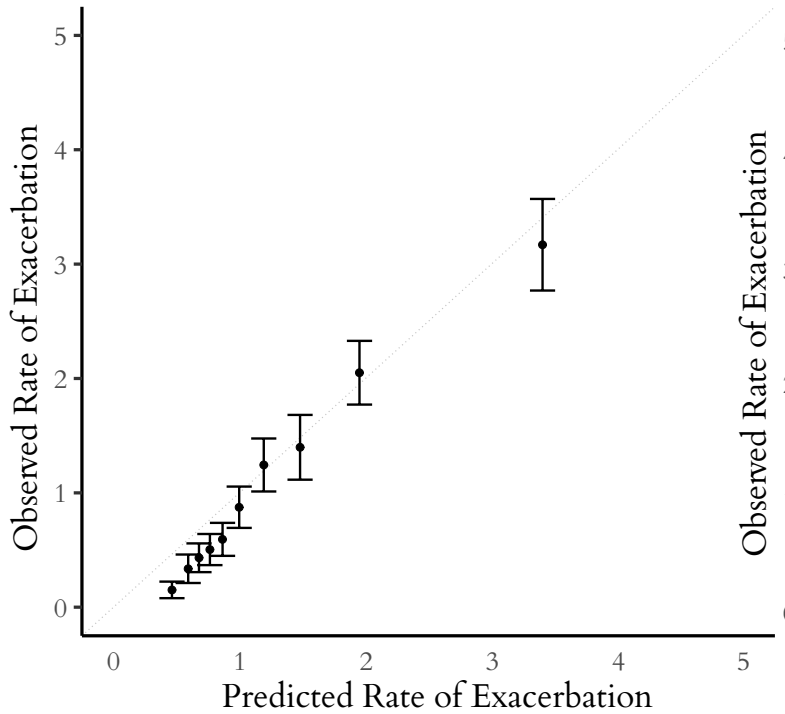

Females $(\mathrm{n}=633)$

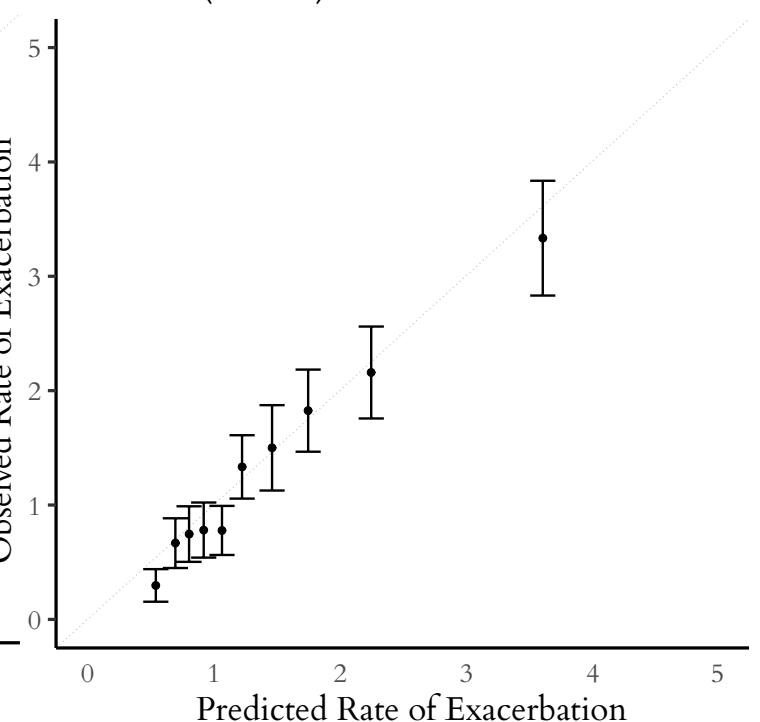

B) In COPD patients with a history of exacerbation in ECLIPSE Study

Males $(\mathrm{n}=611)$

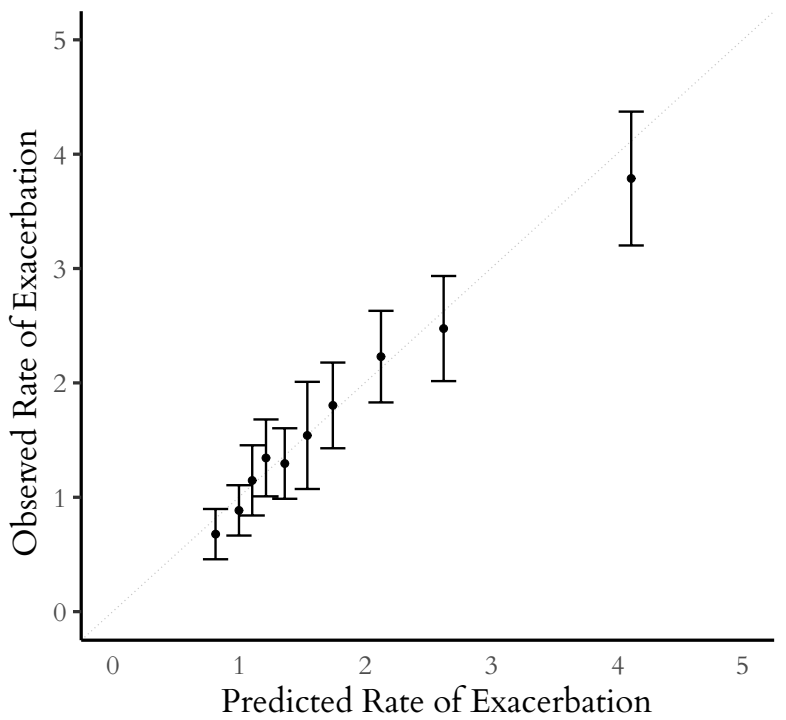

Females $(\mathrm{n}=385)$

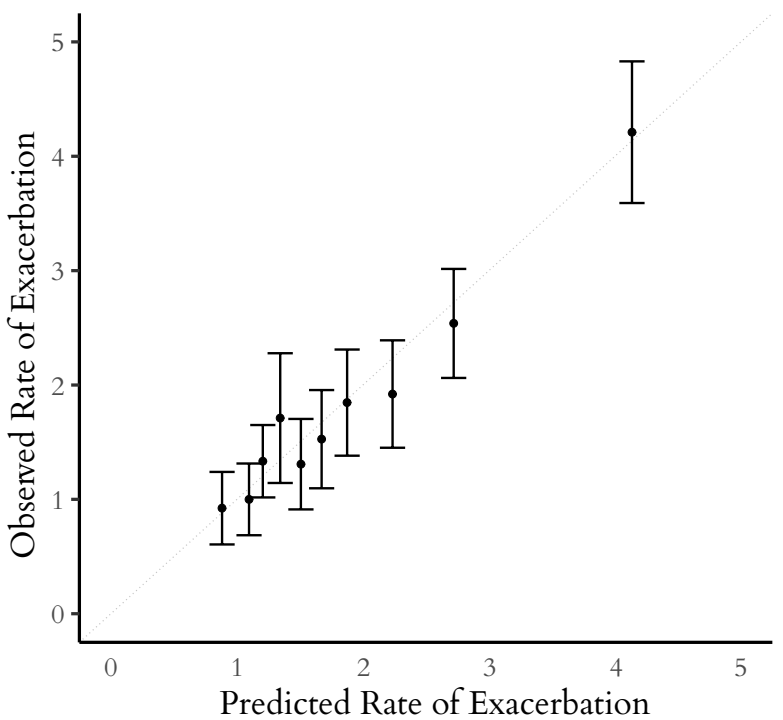

Calibration plot comparing per decile average predicted and observed rate of exacerbations in the external validation dataset.

Figure 4 Calibration plot 


\section{Discriminative ability of ACCEPT compared with event history}

A) In all COPD patients in ECLIPSE Study
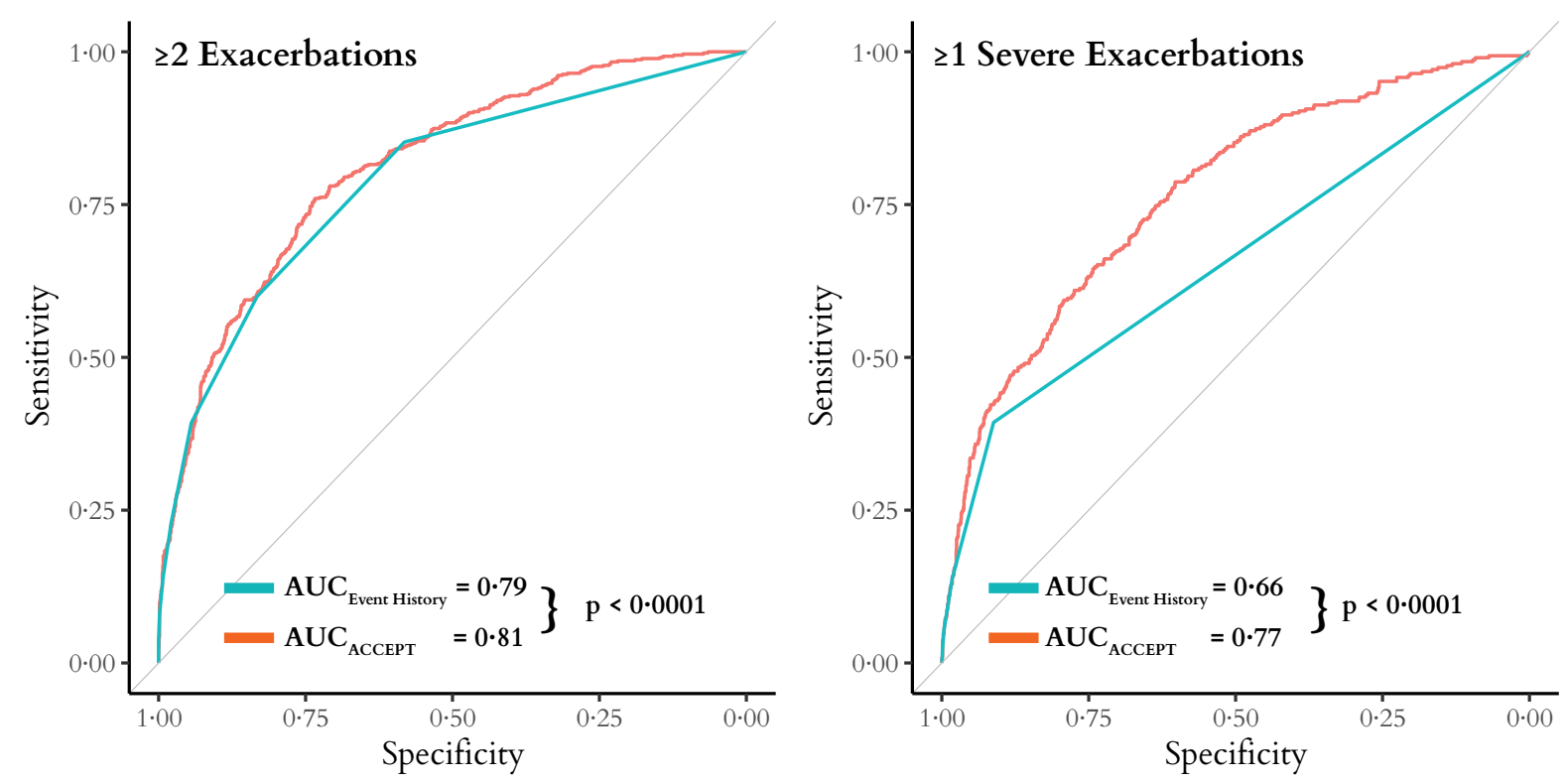

B) In COPD patients with a history of exacerbation in ECLIPSE Study
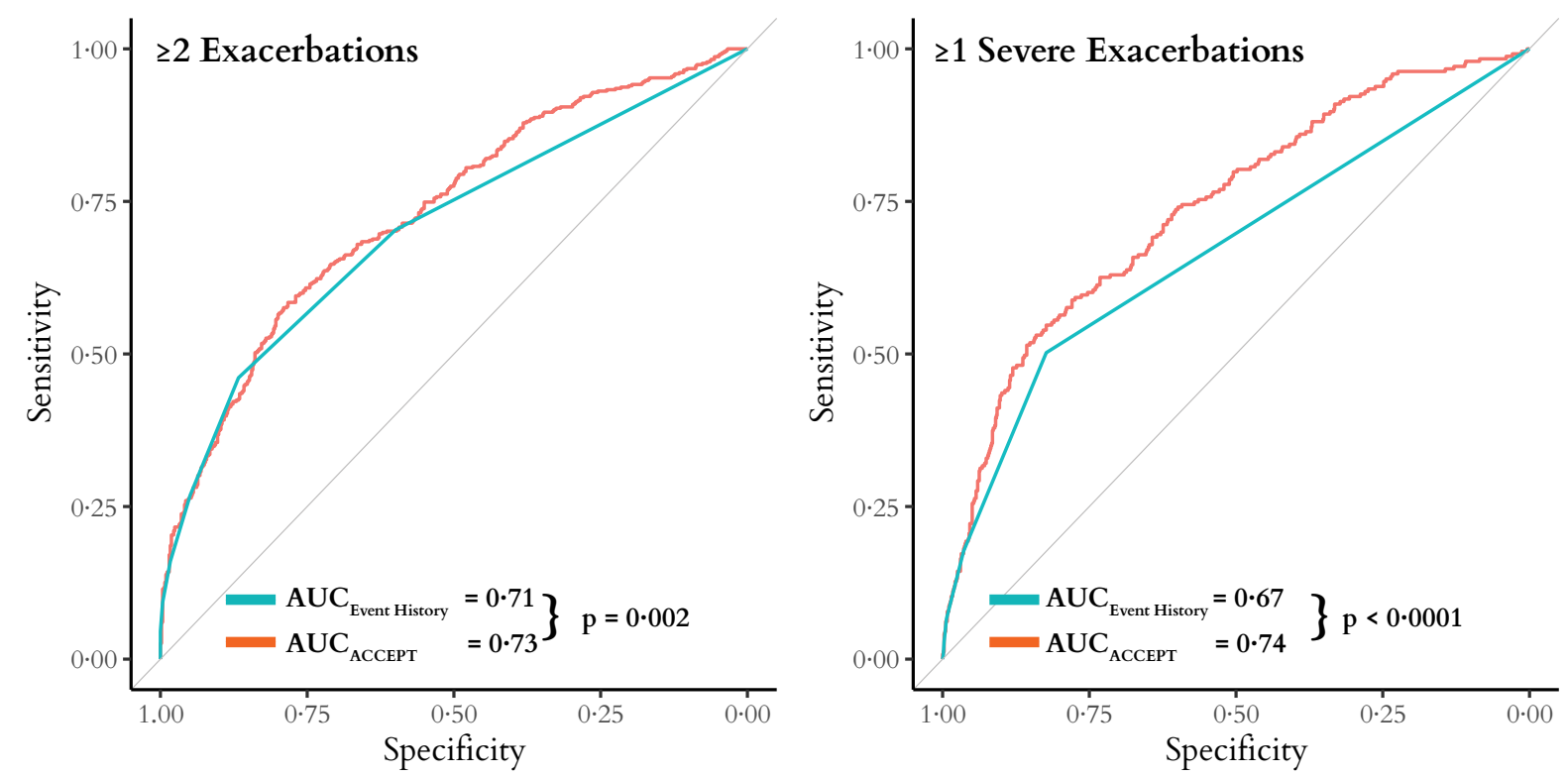

Receiver operating characteristic (ROC) curves showing discriminative performance of ACCEPT compared with last year's history of exacerbation among patients with a prior history of exacerbation and all patients in the external validation dataset. In line with
curves was used to produce p values.

Figure 5 Discriminative ability of ACCEPT compared with event history 


\section{Discussion}

The most important finding of the present study was the development and validation of a model (ACCEPT) that uses simple and widely available clinical and demographic variables to predict the risk and severity of exacerbations over a 12-month period, enabling personalisation of care for patients with COPD. In terms of performance, ACCEPT was superior to the current approach of using the individual's history of exacerbation to predict future risk of exacerbations and in particular for severe exacerbations (where we observed an increase in AUC of $0 \cdot 11$ in all COPD patients and $0 \cdot 07$ in those with an exacerbation in the previous year).

While preventing exacerbations is a major goal in COPD care, there are no tools in practice that can accurately predict the risk or rate of exacerbations in a given individual. Prior studies suggest that patients with a previous history of an exacerbation are more likely to exacerbate in the future than those without. ${ }^{2}$ However, this approach is hampered by a relatively poor resolution, leading to large variations in risk across subjects even among those who have the same history of exacerbations. Our framework builds upon this well-accepted approach and extends its use by incorporating other clinical features that enable a more accurate prediction.

A 2017 systematic review of clinical prediction models for COPD exacerbations found that only two of the 27 reviewed models - CODEX ${ }^{18}$ and Bertens' model $^{19}$ - reported on any external validation. When the availability of predictors and practical applicability were also taken into account, none of the models were deemed ready for clinical implementation. ${ }^{6}$ We are aware of only two additional prediction models published after this review - by $\operatorname{Kerkhof}^{20}$ and Annavarapu $^{21}$ - that have reported external validation. ACCEPT has several notable advantages compared with these models. Importantly, it is externally validated in an independent cohort extending its generalisability beyond therapeutic clinical trials. ACCEPT is also geographically generalisable because the external validation cohort contained data from 12 different countries across North America, Europe, and Oceania. In contrast, previous externally validated models used geographically limited datasets: CODEX was Spanish ${ }^{18}$, Bertens' model was Dutch ${ }^{19}$, Kerkhof's model was British ${ }^{20}$, and Annavarapu's model was based on cross-sectional administrative data from a non-single-payer context in the United States. ${ }^{21}$ Bertens' model, CODEX, and models by Kerkhof and Annavarapu reported validation AUCs of 0.66 and 0.59, $0 \cdot 74$, and $0 \cdot 77$, respectively. However, the independence of the validation dataset in Kerkhof's 
model was questioned as it was selected from the same database as the developmental population. Annavarapu did not report calibration at all, and overall, both models suffered from a lack of generalisability given the local nature of the data that were available to the investigators.

ACCEPT predicts the rate and severity of exacerbations jointly. This is crucial to appropriately tailoring treatments to an individual, as the more granular nature of the output in ACCEPT provides more detailed prediction to assist clinicians in their decision making. For example, ACCEPT can predict the number of exacerbations at a given time period, time to next exacerbation, and the probability of experiencing a specific number of non-severe or severe exacerbations within a given follow-up time (up to one year). This is in contrast to the logistic regression models used in a majority of previous clinical prediction models, which allow prediction probabilities of having at least one exacerbation in a single time window. ${ }^{6}$ Further, this framework can potentially be used for prognostic enrichment of randomised trials by identifying patients who are more likely to exacerbate. Similar to asthma trials, the required sample size and consequently the cost of large trials can be substantially reduced by using prediction models to recruit patients above a certain threshold of expected exacerbation rate. ${ }^{22,23}$

ACCEPT can combine predicted risk with effect estimates from randomised trials to enable personalised treatment. For example, a benefit-harm analysis for roflumilast as preventive therapy for COPD exacerbations reported that the benefits of roflumilast outweighed its potential harm when patients have a severe exacerbation risk of at least $22 \%$ over a year. ${ }^{24}$ Using data from this benefit-harm analysis, the accompanying web app of ACCEPT can be used to inform therapeutic decisions on the use of roflumilast for a given patient. Another example is in the potential use of preventative daily azithromycin therapy in COPD. Azithromycin reduces annual exacerbation rate by $27 \% .{ }^{8}$ However, it is associated with increased risk of hearing impairment and antimicrobial resistance and thus should be reserved for those at a high risk of future exacerbations. ${ }^{8}$ The accompanying web app illustrates this application by showing the risk of exacerbations with and without daily azithromycin therapy in a given patient. Once care providers discuss the risks of harm and benefits of the therapy and establish patient preference thresholds for the benefit/harm trade-off, ACCEPT can be used to determine whether the preventive azithromycin therapy for that individual reaches or surpasses this threshold. 
ACCEPT generates nuanced predictions that allow clinicians to more accurately risk-stratify two patients, who have an identical exacerbation history. The case study in the appendix illustrates this by discussing two patients who have considerably different risk profiles (one projected to experience twice as many severe exacerbations as the other) despite an identical exacerbation history and similar medication profile, smoking status, and age. The complete characteristics of these two patients, as well as prognostic predictions by ACCEPT are available in the appendix ( $\mathrm{p}$ 2).

\section{Limitations}

The pooled trial data we used to develop the model lacked data on certain variables such as comorbidities, vaccination, blood markers (e.g. eosinophil count), and socio-economic status. As such, these predictors could not be incorporated into the model. Moreover, the developmental dataset did not contain individuals without exacerbations in the previous year; however, the model performed robustly in an external validation dataset that included such patients. Neither the developmental nor the validation datasets included patients with mild (GOLD I) severity and as such, we could not establish the accuracy of predictions for this subgroup. Additionally, our model may not be generalisable to COPD patients with a history of asthma, lifetime nonsmokers, patients younger than 40 or older than 80 years of age, or populations outside North America, Europe, and Oceania. Model updating and re-examination of its external validity will be necessary when new sources of data become available. ${ }^{25}$

Compared to simple scoring systems such as the BODE index that can be manually calculated, ACCEPT requires relatively sophisticated computational analysis. While parsimonious models are useful at the bedside, given the complexity of processes involved in the pathogenesis of COPD exacerbations, we believe such tools will have limited resolution. Given the proliferation of hand-held computational devices in clinical practice and the wide availability of clinical parameters that are contained in the model, ACCEPT is usable clinically. This is facilitated through its availability as a web app, a spreadsheet, or the R package 'accept'. ${ }^{26}$

We emphasise that estimates in our model are predictive and should not be interpreted as "causal". The observed association between being a smoker and having a lower exacerbation rate (hazard ratio $0 \cdot 82,95 \%$ CI $0 \cdot 73-0 \cdot 93$ ) is one such example. Smoking is likely a marker of disease severity with sicker patients less likely to smoke than those with milder disease. As such, the 
information in the smoking status variable has high predictive value for the tendency towards exacerbation but is not causally interpretable.

\section{How to Access the Model}

An easy-to-use web application for ACCEPT is available at http://resp.core.ubc.ca/ipress/accept. For any individual patient, the web app predicts 1) the exacerbation risk within the next 12 months, 2) the annual rate of exacerbations, and 3) the probability of experiencing any given number of exacerbations. All outcomes are reported separately for overall and severe exacerbations.

Additionally, we provide an $\mathrm{R}$ package ${ }^{26}$, a spreadsheet template, public application programming interfaces (APIs), and additional code at

\section{http://resp.core.ubc.ca/research/Specific Projects/accept.}

\section{Conclusions}

ACCEPT is an externally validated and generalisable prediction model that enables nuanced prediction of the rate and severity of exacerbations and provides individualised estimates of risks and uncertainty in predictions. ACCEPT has good to excellent discriminatory power in predicting the rate and severity of COPD exacerbations in all COPD patients and showed robust calibration in individuals with a history of such exacerbations in the past year. Objective prediction of outcomes given each patient's unique characteristics can help clinicians to tailor treatment of COPD patients based on their individualised prognosis.

\section{Acknowledgments}

We would like to thank Ainsleigh Hill for her contribution to development and documentation of the R package and co-investigators of the Canadian Institutes of Health Research grant Kelly Ablog-Morrant, Drs. Larry Lynd, Teresa To, Annalijn Conklin, Wenjia Chen, Hui Xie, and the Canadian Thoracic Society for their input and feedback.

\section{Contributors}

MS, DDS, JMF, and SDA conceived the study. AA, AS, and MS developed and validated the model. DDS and SDA contributed to data acquisition. AA, KMJ, AS, JMF, DDS, SDA, and MS contributed to the interpretation of the data. AA wrote the first draft of the manuscript and 
created data visualizations. JMF, DDS, SDA, and MS provided clinical input and oversight. AA developed the Web Application with critical input from KMJ, SDA, DDS, and MS. MS and AA developed the interactive spreadsheet and the R package. All authors revised the manuscript critically and approved the final version to be published.

\section{Declaration of Interest}

Authors declare no conflicts of inter 


\section{References:}

1 Aaron SD. Management and prevention of exacerbations of COPD. BMJ 2014; 349: g5237.

2 Hurst JR, Vestbo J, Anzueto A, et al. Susceptibility to Exacerbation in Chronic Obstructive Pulmonary Disease. N Engl J Med 2010; 363: 1128-38.

3 Vogelmeier CF, Criner GJ, Martinez FJ, et al. Global Strategy for the Diagnosis, Management, and Prevention of Chronic Obstructive Lung Disease 2017 Report. GOLD Executive Summary. Am J Respir Crit Care Med 2017; 195: 557-82.

4 Obeidat M, Sadatsafavi M, Sin DD. Precision health: treating the individual patient with chronic obstructive pulmonary disease. Med J Aust; 0. DOI:10.5694/mja2.50138.

5 Celli BR, Cote CG, Marin JM, et al. The Body-Mass Index, Airflow Obstruction, Dyspnea, and Exercise Capacity Index in Chronic Obstructive Pulmonary Disease. N Engl J Med 2004; 350: 1005-12.

6 Guerra B, Gaveikaite V, Bianchi C, Puhan MA. Prediction models for exacerbations in patients with COPD. Eur Respir Rev 2017; 26: 160061.

7 Collins GS, Reitsma JB, Altman DG, Moons K. Transparent reporting of a multivariable prediction model for individual prognosis or diagnosis (TRIPOD): the TRIPOD Statement. BMC Med 2015; 13: 1.

8 Albert RK, Connett J, Bailey WC, et al. Azithromycin for prevention of exacerbations of COPD. N Engl J Med 2011; 365: 689-98.

9 Criner GJ, Connett JE, Aaron SD, et al. Simvastatin for the Prevention of Exacerbations in Moderate-toSevere COPD. N Engl J Med 2014; 370: 2201-10.

10 Aaron SD, Vandemheen KL, Fergusson D, et al. Tiotropium in Combination with Placebo, Salmeterol, or Fluticasone-Salmeterol for Treatment of Chronic Obstructive Pulmonary Disease: A Randomized Trial. Ann Intern Med 2007; 146: 545.

11 Agusti A, Calverley PM, Celli B, et al. Characterisation of COPD heterogeneity in the ECLIPSE cohort. Respir Res 2010; 11: 122.

12 Hankinson JL, Odencrantz JR, Fedan KB. Spirometric reference values from a sample of the general U.S. population. Am J Respir Crit Care Med 1999; 159: 179-87.

13 Morishita-Katsu M, Nishimura K, Taniguchi H, et al. The COPD assessment test and St George's Respiratory Questionnaire: are they equivalent in subjects with COPD? Int J Chron Obstruct Pulmon Dis 2016; 11: 1543-51.

14 Sadatsafavi M, Sin DD, Zafari Z, et al. The Association Between Rate and Severity of Exacerbations in Chronic Obstructive Pulmonary Disease: An Application of a Joint Frailty-Logistic Model. Am J Epidemiol 2016; 184: 681-9.

15 Ewout Steyerberg. Clinical Prediction Models - A Practical Approach to Development, Validation, and Updating. Springer New York, 2009. 
16 Steyerberg EW, Vickers AJ, Cook NR, et al. Assessing the Performance of Prediction Models: A Framework for Traditional and Novel Measures. Epidemiology 2010; 21: 128-38.

17 DeLong ER, DeLong DM, Clarke-Pearson DL. Comparing the areas under two or more correlated receiver operating characteristic curves: a nonparametric approach. Biometrics 1988; 44: 837-45.

18 Almagro P, Soriano JB, Cabrera FJ, et al. Short- and Medium-term Prognosis in Patients Hospitalized for COPD Exacerbation: The CODEX Index. Chest 2014; 145: 972-80.

19 Bertens L, Reitsma, Moons, et al. Development and validation of a model to predict the risk of exacerbations in chronic obstructive pulmonary disease. Int J Chron Obstruct Pulmon Dis 2013; : 493.

20 Kerkhof M, Freeman D, Jones R, Chisholm A, Price D. Predicting frequent COPD exacerbations using primary care data. Int J Chron Obstruct Pulmon Dis 2015; : 2439.

21 Annavarapu S, Goldfarb S, Gelb M, Moretz C, Renda A, Kaila S. Development and validation of a predictive model to identify patients at risk of severe COPD exacerbations using administrative claims data. Int J Chron Obstruct Pulmon Dis 2018; Volume 13: 2121-30.

22 FitzGerald JM, Sadatsafavi M. Improving precision in the prediction of asthma exacerbations. Lancet Respir Med 2017; 5: 539-40.

23 Fuhlbrigge AL, Bengtsson T, Peterson S, et al. A novel endpoint for exacerbations in asthma to accelerate clinical development: a post-hoc analysis of randomised controlled trials. Lancet Respir Med 2017; 5: 57790 .

$24 \mathrm{Yu}$ T, Fain K, Boyd CM, et al. Benefits and harms of roflumilast in moderate to severe COPD. Thorax 2014; 69: 616-22.

25 Moons KGM, Kengne AP, Grobbee DE, et al. Risk prediction models: II. External validation, model updating, and impact assessment. Heart Br Card Soc 2012; 98: 691-8.

26 Adibi A, Sadatsafavi M, Hill A. accept: The Acute COPD Exacerbation Prediction Tool (ACCEPT). 2019 https://CRAN.R-project.org/package=accept (accessed Sept 30, 2019). 